\title{
PHYSICAL PROPERTIES OF WATER-OIL MIXTURES INVOLVING WAXING
}

\author{
LIYUN LAO \& MARVELOUS AGUNLOYE \\ Process Systems Engineering, Cranfield University, UK
}

\begin{abstract}
Non-Newtonian fluids exist extensively in the oil and gas industry and possess distinct physical properties that differ from those of Newtonian fluids. The multiphase flow involving non-Newtonian fluids have posed a serious challenge to the industry; however, comprehensive information expressing a wider knowledge of the mixture properties have not been well acquired. The focus of this paper is on water-oil mixtures involving petroleum wax, and seeks to highlight the waxing issue which is frequently encountered in offshore oil and gas transport pipelines. Experimental tests are carried out to investigate the behaviour of the water-oil mixture (with wax composition) and examine their fundamental physical and rheological properties. Furthermore, the effect of changes in temperature and varying water volume fraction on the shear rate - shear stress characteristics of the mixture are also considered. Results from this study show that the mixture properties depend significantly on temperature changes, fluid composition and the water content. Investigations also suggest that the phase inversion phenomenon has a significant impact on the shear rate-shear stress characteristics of the non-Newtonian oil/water mixture.
\end{abstract}

Keywords: multiphase, temperature, water content, shear rate, shear stress, viscosity, phase inversion.

\section{INTRODUCTION}

The continuous and undisturbed flow of oil from the reservoir to storage is of major importance in the oil and gas industry. However various environmental factors and conditions influence the smooth flow during production and transportation.

Typical fluid produced from the reservoir by its nature is multiphase, due to the presence of more than one component in the mixture. Produced crude exists as emulsions and in many case is composed of oil, dissolved gas, water and sediments [1], [2]. These emulsions exhibit various macroscopic physical properties influenced by their composition, average emulsion size and the individual viscosity of their respective phases, which may vary with applied shear stress and temperature [1]. Adequate understanding of the fluid phases present is required to characterise the fluid flow behaviour as well as plan effectively for transportation and storage.

For a mixture of two or more immiscible fluids, the combined physical properties are modified and differ extensively from the properties of just a single individual fluid stream. Govier \& Aziz [3] show that the resultant flow results in a rich phase illustrated by suspended droplets, bubbles or slugs. The flow behaviour is therefore dependent on the interfacial, inertia and viscous forces.

Light hydrocarbons at standard temperature and pressure often exhibit Newtonian fluid characteristics [4], though variations in viscosity may exist. However, the presence of impurities and/or heavier carbon components could significantly alter its resistance to flow. The presence of impurities such as dissolved wax formed under appropriate environmental conditions can also lead to this exceptional fluid behaviour known as non-Newtonian [1]. The continuous wax build-up in production equipment potentially restricts flow and reduces fluid volume produced. The resulting wax deposits have been identified as a major flow assurance problem and could cause other start-up problems as well. 
The wax present in crude oils is composed mainly of paraffin and naphthenic hydrocarbons [5]. Early literature suggests that waxy crudes are highly non-Newtonian fluids with complex flow properties which depend on factors such as the temperature and shear rate [6], [7]. Further research by Al-Zahrani and Al-Fariss [7], show that certain crudes that exhibit non-Newtonian behaviour have their rheological properties greatly influenced by the wax concentration in addition to the temperature and shear rate. Adeyanju and Oyekunle [8] report that at temperatures above the wax appearance temperature (WAT), wax readily dissolves in the oil matrix and hence the fluid still exhibits Newtonian behaviour, but when the temperature falls below the WAT - typically at low temperatures below ambient point - the heavier fractions begin to precipitate and solid wax crystals begin to form in the crude. Further reduction in temperature will enhance the formation of precipitated wax crystals and the fluid begins to exhibit non-Newtonian behaviour [9], [10].

However, it is suggested that the key factor that governs the rheological properties of waxy crudes is the concentration of the precipitated wax rather than the wax content as the first wax crystals have limited impact on viscosity and rheology until a certain fraction where significant shear rate dependency begins to develop [4], [11]. Li and Zhang [11] posit that thus technically the presence of wax has little effect on the oil viscosity above the WAT.

Other experiments have been undertaken to study the fluid behaviour and interaction of oil and gas flow, but comprehensive knowledge of multiphase liquid-liquid mixtures involving non-Newtonian fluids have not been well acquired and they still pose a challenge to the industry.

Equally important as the presence of wax in the investigation of the fluid behaviour of the crude is the shear mechanism and thermal history experienced during any prior treatment of the oil [6], [12]-[14]. These factors significantly influence the rheology of waxy crudes and adequate care should be taken during measurement and data interpretation.

While studying the impact of water on the gelation and rheology of waxy crudes, Visintin et al. [15] report that although the effect of dispersed water on crude oil rheology had been well characterised, little attention has been given to the study of the potential impact of emulsified water on crude oil gelation. Their study shows that the presence of water can enhance greatly the formation of gel, the pour point temperature and its yield strength. The effect of water cut on the viscosity of waxy crudes was identified, revealing the phase inversion phenomenon [16].

This paper is therefore concerned with the experimental study of this sort of liquid-liquid multiphase mixtures involving non-Newtonian crude, to measure the fundamental physical properties and flow behaviour, examine the shear stress-shear rate characteristics of the mixture at different temperatures and water cut, as well as the effects of these parameters on viscosity. For the bench tests, the selected wax (Petrolatum) is emulsified with oil to simulate non-Newtonian fluid behaviour at different wax concentrations and water volume fractions.

The relationship between the temperature, the amount of water and the viscosity of the waxy oil is shown in this study, revealing that above a certain threshold of water volume, the presence of water can significantly alter the viscosity of the non-Newtonian water-oil mixture.

\section{EXPERIMENTAL SETUP AND PROCEDURE}

The experiment was carried out in the Process Systems Engineering (PSE) laboratory of Cranfield University to study the fundamental physical properties of a non-Newtonian wateroil mixture. The procedure includes an experiment to investigate the shear rate-shear stress characteristics of the mixture, at different discrete temperatures and water cut values. 
For proper investigation and scientific reporting of result, the experiment is sub-divided into these steps;

1. An initial test to characterise the physical properties of the base fluid sample.

2. Test to determine the physical properties of the oil and wax mixture.

3. Further investigation to evaluate the physical properties of oil, wax and water mixture.

\subsection{Experimental apparatus}

The test for the physical and rheological properties of the mixture samples was carried out using the Brookfield Digital Viscometer (Model LVDV-I PRIME) with spring torque of 673.7 dyne-cm $(0.0673 \mathrm{mN}-\mathrm{m})$. This rotational viscometer, suitable for low viscosity fluids measures the fluid's resistance to flow (viscosity) for any given shear rate.

Emulsification was performed using the UP200S stand-mounted ultrasonic homogenizer at an output amplitude of $100 \%$ for an average of 5 minutes. This was to ensure even distribution of the particles in the mixture sample and create a homogenous, stable and evenly distributed mixture. For this particular experimental test, the S40 sonotrode with an immersion depth of up to $200 \mathrm{~mm}$ suitable for applications of this nature is used to enable adequate mixing of the sample volume.

A water bath relying primarily on convection for heat transfer was employed to incubate samples in water at a set temperature range over a period of time, this is to investigate the effect of changes in temperature on other physical properties of the liquid-liquid mixture.

\subsection{Experimental setup and procedure}

To investigate the physical properties of the liquid-liquid non-Newtonian fluid mixture, the samples are prepared and tested to determine the shear stress-shear rate characteristics of the mixture, at different temperatures and water cut values using the LVDV-I Prime Viscometer.

In performing the experiment, two spindle sizes LV \#61 and \#62 were found to be suitable for the experimental procedure over various speeds relative to the viscosity range of the sampled fluid. At higher speeds, stable viscosity readings were obtained using the larger spindle (LV \#61).

A reference test was carried out to observe the sensitivity of the petrolatum wax to changes in temperature. The samples were heated to a temperature of $80^{\circ} \mathrm{C}$, with the viscosity readings taken at discrete temperature intervals and at different rotational speeds. This initial test on

Table 1: Recorded parameters for repeatability and reproducibility.

\begin{tabular}{|l|l|l|}
\hline Parameters & Value \\
\hline Viscometer Model & DV-I PRIME & $\# 61$ \\
\hline Spindle Size & $\# 62$ & $1000 \mathrm{~mL}$ \\
\hline Beaker Size & $1000 \mathrm{~mL}$ & $700 \mathrm{~mL}$ \\
\hline Volume of Fluid (wax) & $500 \mathrm{~mL}$ & $20,30,50,60,100$ \\
\hline Motor Speed (RPM) & $20,30,50,60,100$ & 4 \\
\hline $\begin{array}{l}\text { Spindle Turn duration interval } \\
\text { (minutes) }\end{array}$ & 4 & 80 \\
\hline Water Bath Temperature $\left({ }^{\circ} \mathrm{C}\right)$ & 80 & \multicolumn{2}{|l|}{} \\
\hline
\end{tabular}


the base sample is to serve as a reference for further investigations and to confirm the repeatability and reproducibility of the experiments.

Further investigations were performed to determine the effect of the wax concentration on the mixture properties, as well as the effect of shear mechanism, temperature and water volume on the viscosity of the different samples.

Fig. 1 illustrates a schematic of the experimental procedure followed.

\subsubsection{Experimental test fluids}

The test was carried out using fluids which are environmentally friendly, safe and suitable for laboratory use. The following working fluids were used for the experiment and their physical properties are discussed in Table 2:

- EDM-3 fluid to simulate oil behaviour

- Petrolatum wax to induce non-Newtonian behaviour in the oil

- Distilled water

\subsubsection{Sample preparation}

The mixtures were prepared using ASTM standard procedures (ASTM D5854-96) to ensure repeatability and reproducibility. The rheological measurements for all fluid samples were carried out with the Brookfield Rotational Viscometer Model LVDV-I PRIME with spindles LV \#61 and LV \#62.

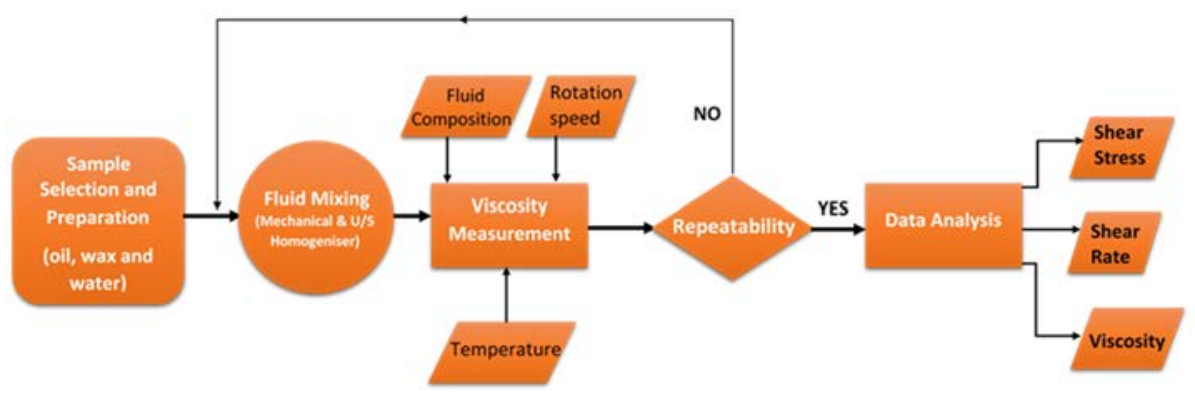

Figure 1: Methodology of experimental procedure.

Table 2: Selected physical properties of test fluids at standard temperature and pressure.

\begin{tabular}{|l|l|l|l|}
\hline Parameter & EDM-3 Oil & Petrolatum wax & Distilled water \\
\hline ID number & CAS No 64742-46-7 & CAS No 8009-03-8 & \\
\hline State/ Appearance & Liquid & Paste & Liquid \\
\hline Colour & Amber & Amber & Colourless \\
\hline $\begin{array}{l}\text { Relative density } \\
\left(\mathrm{Kg} / \mathrm{m}^{3}\right) \text { at } 15^{\circ} \mathrm{C}\end{array}$ & 0.812 & $0.865-0.886$ & 0.998 \\
\hline Viscosity $(\mathrm{mPa} . \mathrm{s})$ & 7 & Varies & 1 \\
\hline $\begin{array}{l}\text { Surface tension } \\
(\mathrm{mN} / \mathrm{m})\end{array}$ & 28.7 & & 32 \\
\hline Solubility & Miscible in water & $\begin{array}{l}\text { Insoluble in water, } \\
\text { miscible in oil }\end{array}$ & \\
\hline Boiling Point $\left({ }^{\circ} \mathrm{C}\right)$ & $277-320$ & $360-732$ & 100 \\
\hline Melting Point $\left({ }^{\circ} \mathrm{C}\right)$ & $<-5$ & $51-71$ & 0 \\
\hline
\end{tabular}


To investigate the effects of temperature and water cut on non-Newtonian liquid-liquid mixtures, sample volumes of the base fluids (oil and wax) were first prepared and their properties defined, before being combined and evaluated as fluid mixtures.

Oil sample $-300 \mathrm{~mL}$ of Pure EDM-3 fluid was put into a $1000 \mathrm{~mL}$ Fisher-brand beaker and heated to a temperature of $80^{\circ} \mathrm{C}$, then allowed to cool down while taking viscosity measurements at discrete temperature points and at different rotational speeds. The low viscosity ranges of the fluid required the use of spindle LV \#62 and LV \#61 for accurate measurement.

Petrolatum Wax - The petrolatum wax samples were prepared using guidance from ASTM standard test methods D445-15a and D2669-06 to determine the apparent viscosity at discrete temperature point. $500 \mathrm{~g}$ and $700 \mathrm{~g}$ of wax were melted into a $1000 \mathrm{ml}$ beaker, heated to a temperature of $80^{\circ} \mathrm{C}$ in a temperature controlled water bath and allowed to cool down as viscosity measurement are taken (using spindles LV \#62 and LV \#61 respectively). The sample is mechanically stirred continuously to ensure homogeneity.

Oil and wax mixture - The waxy oil samples were prepared by adding the petrolatum wax to a defined amount of EDM-3 oil. Four (4) samples of oil and wax mixture at different wax concentrations were prepared to simulate waxy non-Newtonian crude. The wax is added in concentrations of $10 \%, 20 \%, 37.5 \%$ and $50 \mathrm{wt} . \%$ of the total sample volume. Each separate sample is stirred mechanically and ultrasonically (with the aid of a U/S homogenizer) to achieve a homogenised mixture, this homogenised mixture is then heated to a temperature of $80^{\circ} \mathrm{C}$ and allowed to cool down with viscosity measurements taken at discrete temperature points. The viscosity of the mixture is taken at different rotational speeds $(20,30,50,60$ and 100 RPM).

Oil, wax and water emulsion - To prepare the oil, wax and water emulsion, water was added in varying quantities to each fluid sample prepared above. Experimental tests were then carried out on the emulsion mixtures, to investigate the effect of water fraction on the physical properties of the liquid-liquid non-Newtonian oil sample. For the experiment, different water-oil (W/O) emulsions were prepared with water cut ranging from $5 \%$ to $50 \%$ in each sample. The samples were then tested at various discrete temperatures and rotation speed.

\subsubsection{Experimental viscosity measurements}

The viscosity measurements were performed over a rotational speed range of 20 to 100 RPM at different temperatures while observing the effect of wax concentration and water volume fraction on the mixture viscosity.

The analysis of the results shows the viscosity-temperature relationship, the shear stress shear rate relationship, the effect of wax concentration on the physical properties and the effects of water fraction on mixture viscosity.

\section{RESULTS AND DISCUSSION}

\subsection{Base fluids}

It is important to measure the viscosity of the base fluids used prior to preparing the emulsion, as it will provide a basis to compare the changes and the effect of addition constituents on the physical properties. It also provides a means of confirming the repeatability and reproducibility of the experiment by performing the same thermal cycle tests repeatedly and comparing the results obtained. 


\subsubsection{Fluid behaviour of base samples}

An analysis of the shear stress-shear rate relationship of the EDM-3 fluid shows constant viscosity as the shear rate is varied for any given temperature point. Investigations to determine the fluid behaviour of the petrolatum wax confirms its non-Newtonian characteristics. Fig. 2 illustrates the shear stress - shear rate relationship for the petrolatum wax sample.

\subsubsection{Viscosity-temperature relationship}

The temperature of the wax sample had a significant effect on the viscosity. At a fixed shear rate, the viscosity decreases with temperature. The extent of this decrease was more evident at lower shear rates than at higher values. Fig. 3 illustrates this relationship between the viscosity and temperature of the petrolatum wax at different shear rates.

\subsection{Non-Newtonian oil mixture}

The mixture of the EDM-3 fluid and petrolatum wax produces a non-Newtonian fluid mixture; this simulates a typical waxy or heavy crude oil in the reservoir. Four samples at different wax concentrations were prepared for testing.

\subsubsection{Effect of temperature on the viscosity}

At a fixed concentration of wax, the influence of temperature changes on the wax-in-oil mixture is visible as shown in Fig. 4. At high temperature, the mixture shows Newtonian fluid behaviour as the change in shear stress with shear rate is constant while the viscosityshear rate plot shows a straight line. As the temperature of the mixture reduces, wax crystallization occurs and the mixture begins to display non-Newtonian fluid properties.

\subsubsection{Effect of wax concentration on the viscosity-temperature relationship}

Increasing the wax concentration in the pure sample from 0 to $100 \%$ while keeping the shear rate fixed at 100 RPM, shows a general increase in the viscosity profile as seen in Fig. 5. The viscosity profile shows that the concentration of wax present significantly affects the viscosity of the mixture, especially below the WAT.

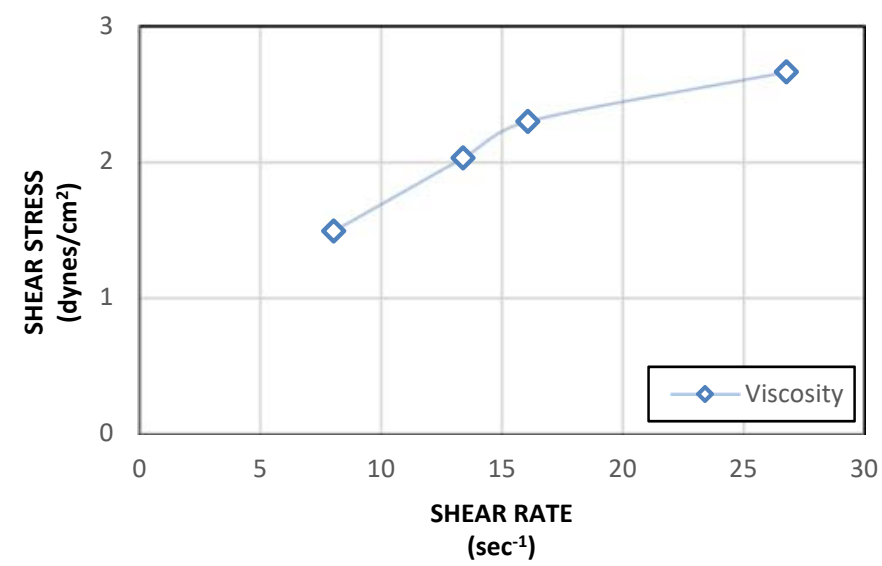

Figure 2: Shear stress-shear rate relationship exhibited by Petrolatum wax at $50^{\circ} \mathrm{C}$. 


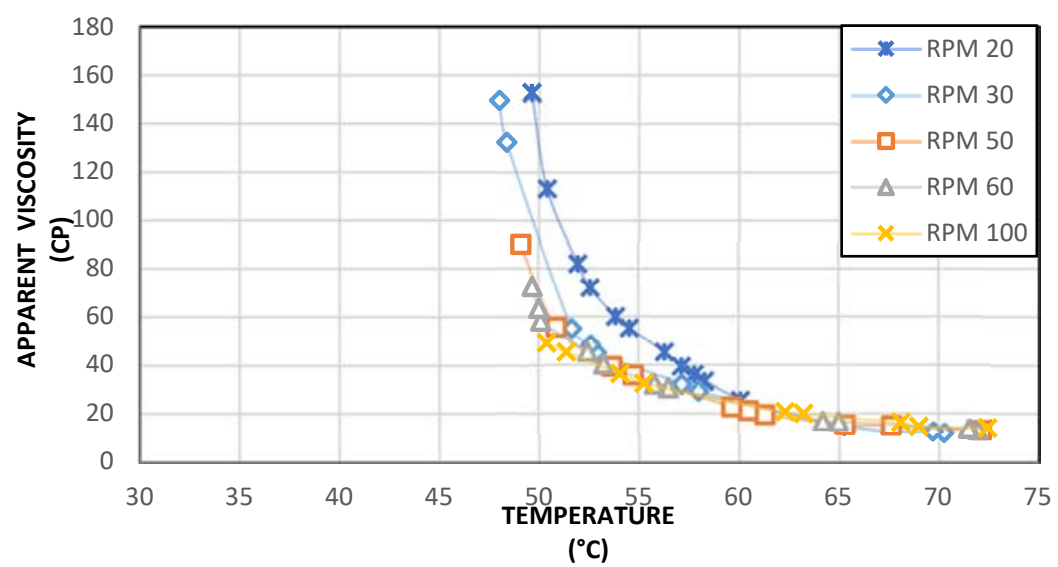

Figure 3: Effect of temperature on Petrolatum wax viscosity.

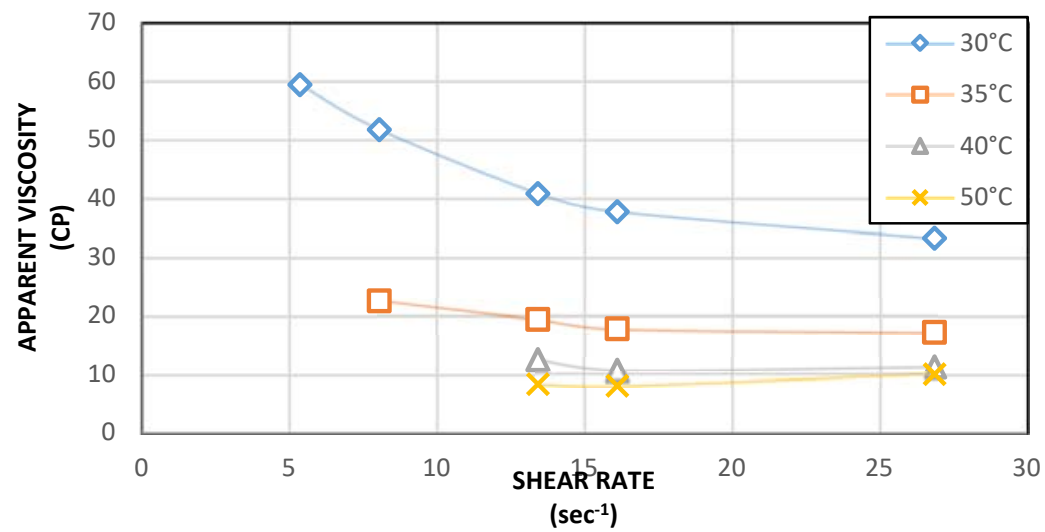

Figure 4: Effect of temperature variations on the viscosity at fixed wax concentration (37.5\% wax in oil).

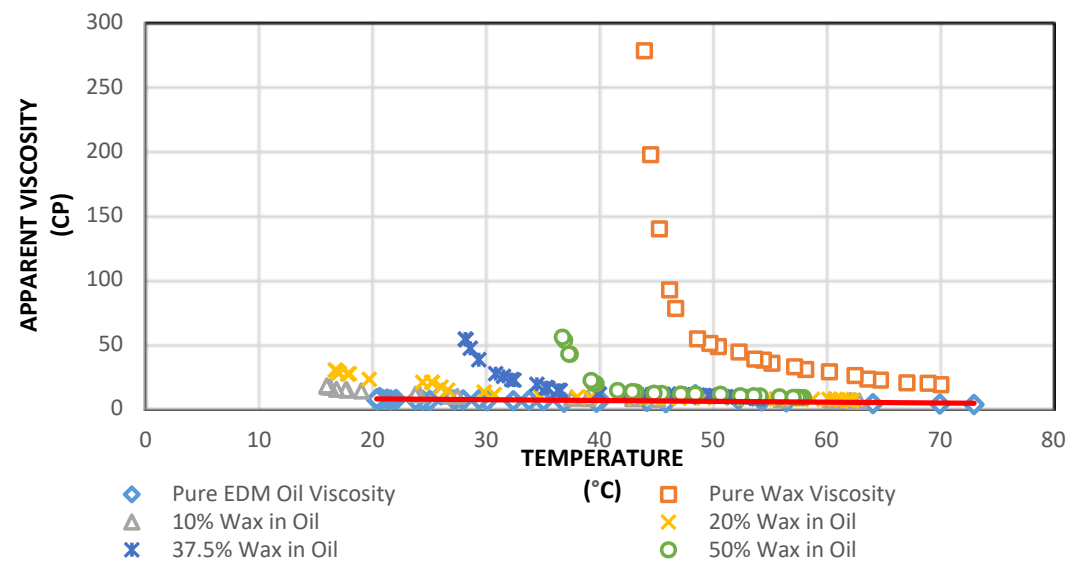

Figure 5: Effect of wax concentration on the non-Newtonian mixture. 


\subsubsection{Effect of wax concentration on fluid behaviour}

At a fixed temperature above the WAT, Newtonian behaviour can be noticed in the mixture sample with wax concentration $(10 \mathrm{wt} . \%)$ while the sample with the highest wax concentration (50 wt.\%) quickly begins to exhibit non-Newtonian behaviour as the rate of shear increases (Fig. 6).

\subsection{Water in waxy oil emulsion}

The water in waxy oil emulsion represents the liquid-liquid mixture involving nonNewtonian fluid. The samples are prepared using the procedure already outlined in section 2.2.2, the water content volume of the mixture is increased from 0 to $50 \%$ (in incremental volumes of 5, 10, 20, 40 and 50\%). The results for the additions to low and high wax concentrations are discussed in sections 3.3.1 to 3.3.2.

\subsubsection{Effect of water content on the viscosity-temperature relationship}

The presence of increased water fraction volume generally caused a reduction in the viscosity of the mixture. Fig. 7 and Fig. 8 show the effect of water content fraction on the viscosity profile for low wax and high wax concentrations respectively.

\subsubsection{Effect of water content fraction on the mixture viscosity}

The impact of the presence of water on the fluid behaviour of the non-Newtonian oil and wax mixture was investigated by measuring the apparent viscosity at 5, 10, 20, 40 and 50\% water fractions. The result is compared with the same mixture without water ( $0 \%$ water content) and is presented in Fig. 9. It can be observed that the water content has a significant effect on the non-Newtonian fluid properties, especially at high water-cut values. Typically, the presence of water causes a reduction in the viscosity of waxy crudes as can be seen from $0 \mathrm{wt} . \%$ to $10 \mathrm{wt} . \%$ water fractions. However, experimental results reveal that the apparent viscosity of the oil, wax and water emulsion increases sharply after this initial reduction in emulsion viscosity. This increase in viscosity is visible above $10 \mathrm{wt} . \%$ water fractions as shown in Fig. 10 and Fig. 11.

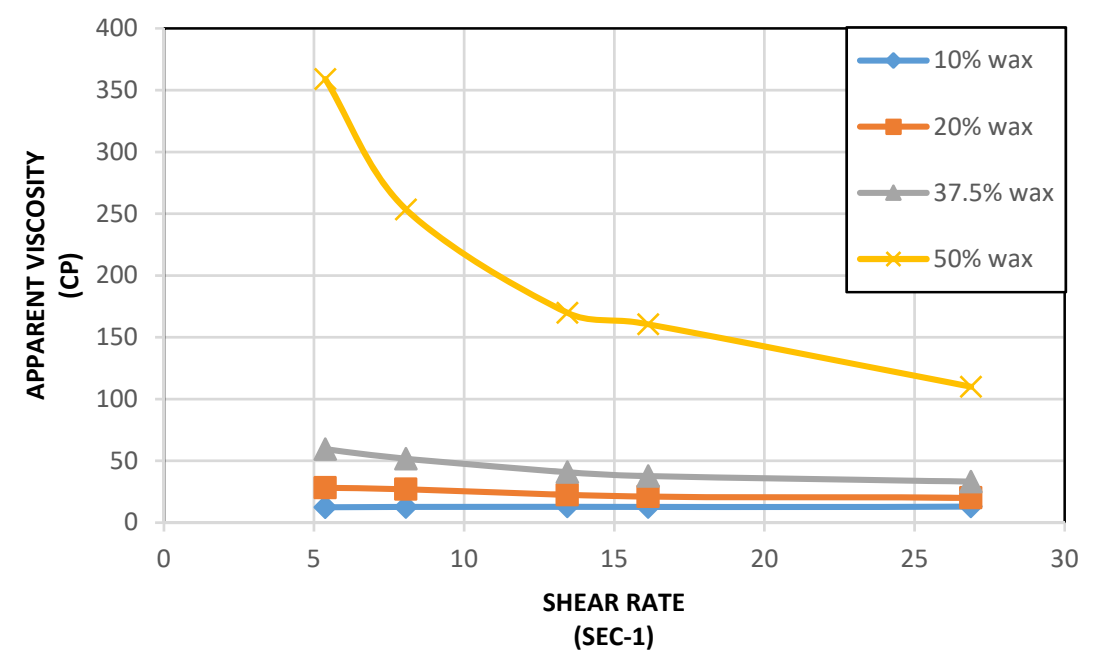

Figure 6: Effect of shear rates at different wax concentration on the mixture viscosity. 


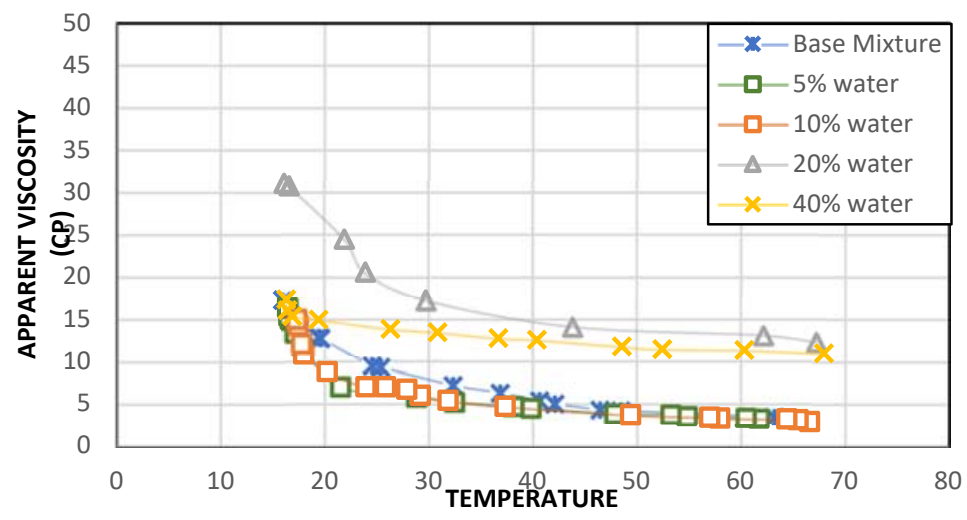

$\left({ }^{\circ} \mathrm{C}\right)$

Figure 7: Effect of temperature on the mixture viscosity at different water content for low wax concentration.

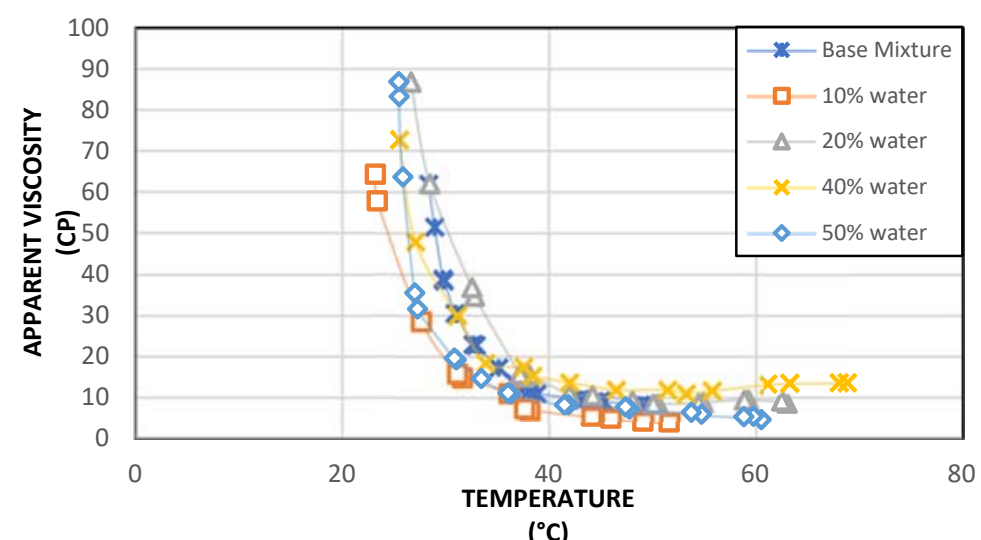

Figure 8: Effect of temperature on the mixture viscosity at different water content for high wax concentration.

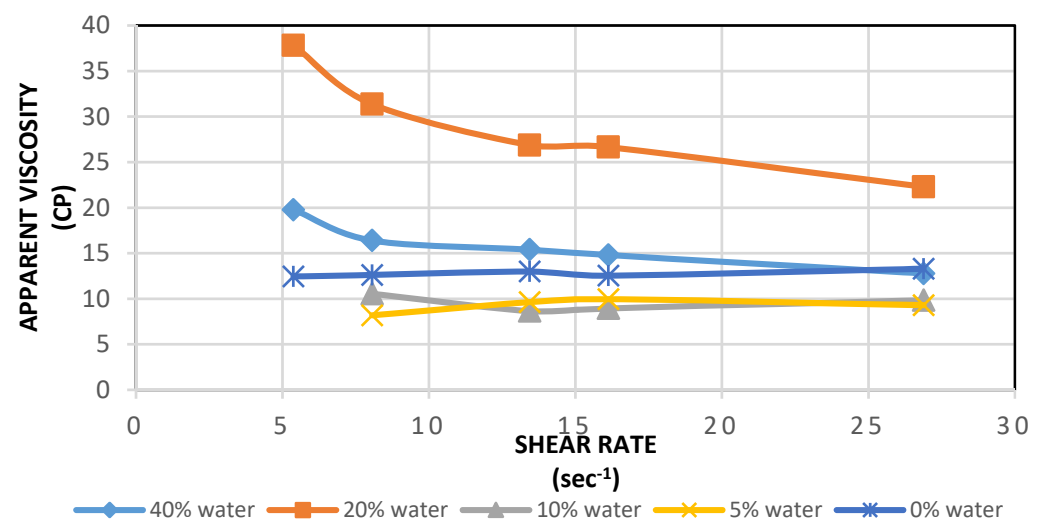

Figure 9: Effect of shear rate at different water volume fractions on the mixture viscosity for low wax concentration. 


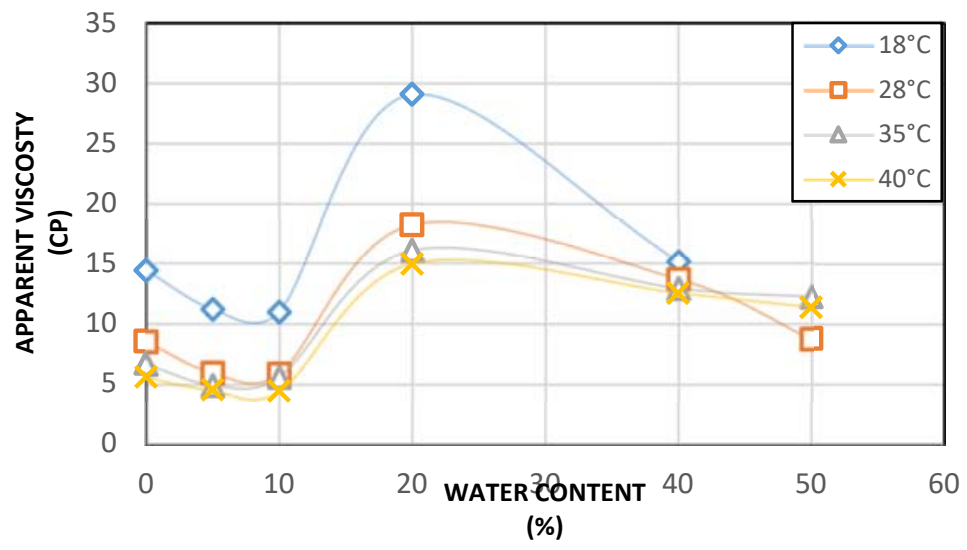

Figure 10: Effect of water content on the mixture viscosity at varying temperatures for low wax concentration.

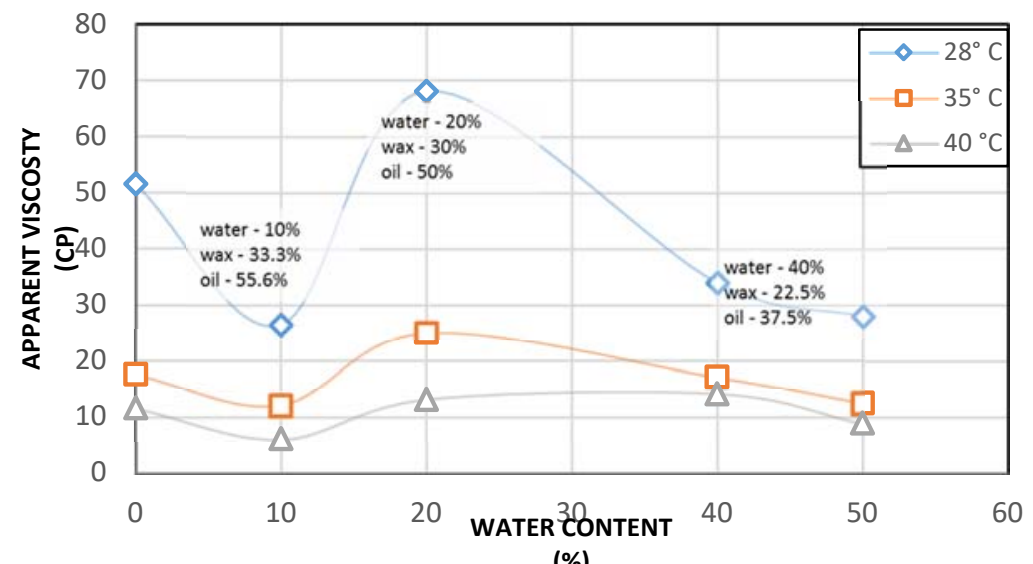

(\%)

Figure 11: Effect of water content on the mixture viscosity at varying temperatures for high wax concentration.

This change in viscosity profile has been attributed to the phase inversion point where the mixture begins to deviate from a water-in-oil mixture to an oil-in-water mixture as the mixture experiences an increase in the quantity of the dispersed fluid. The maximum viscosity of the mixture occurs at the point of phase inversion ( $20 \%$ water cut fraction).

Observation from the low and high wax concentration shows that this phenomenon is more pronounced at very low temperatures.

\section{CONCLUSIONS}

This study investigated the effect of temperature and water-cut on the physical properties of liquid-liquid (water-oil) mixtures involving non-Newtonian fluids.

Using Petrolatum wax to simulate non-Newtonian behaviour in the oil mixture, the fluid behaviour of the wax-in-oil was measured and indicated a non-Newtonian, pseudo-plastic shear thinning behaviour typical of waxy crudes. This mixture was further tested for the effect 
of water cut and temperature variation at various shear rates. Based on the shear stress and shear rate characteristics, it was observed that the temperature, wax concentration and water volume fraction had a significant effect on the behaviour of the mixture.

The water volume fraction impacts significantly on the mixture viscosity between 10 to $20 \mathrm{wt} . \%$ water-content, indicating either a phase inversion region or a partial separation of the oil and water phases within the emulsion mixture. This implies that an increase in the volume of the dispersed phase in the mixture can alter the fluid behaviour, especially where the physical property is strongly dependent on the rate of shear, thus influencing the shear stress-shear rate characteristics. The following conclusions can be drawn:

- The wax concentration has a significant effect on the viscosity profile of the mixture and fluid behaviour, as there is a significant increase in viscosity with increasing wax concentration.

- The wax-in-oil mixture exhibits non-Newtonian behaviour at low ambient temperatures, however as temperatures begin to rise, the mixture shows Newtonian characteristics above the WAT irrespective of the wax concentration.

- The addition of water into the wax-in-oil emulsion decreases the mixture viscosity up to the phase inversion region where a higher fluid viscosity is observed.

- The maximum viscosity of the mixture is observed at the phase inversion point.

\section{ACKNOWLEDGEMENTS}

The authors are grateful to Cranfield University Oil and Gas Engineering Centre for the use of the Process Systems Engineering laboratory where all experimental activities took place. Our sincere appreciation also goes to Mr. Stan Collins of the PSE Lab and Nonso Okeke for their assistance throughout the project duration.

\section{REFERENCES}

[1] Becker, J.R., Crude Oil Waxes, Emulsions and Asphaltenes. Tulsa, PennWell Books: Oklahoma, 1997.

[2] Giles, H.N., Crude Oils. Significance of Tests for Petroleum Products, 8, pp. 106-122, 2010,

[3] Govier, G.W. \& Aziz, K., The Flow of Complex Mixtures in Pipes, 2. R.E Krieger Publishing Company: Huntington, N.Y., 1977.

[4] Rønningsen, H.P., Rheology of Petroleum Fluids. Annual Transactions of The Nordic Rheology Society, 20, pp. 11-18, 2012.

[5] Mansoori, G.A., Barnes, H.L. \& Webster, G.M., Petroleum Waxes, Fuels and Lubricants Handbook, pp. 525-558, 2003.

[6] Rønningsen, H.P., Rheological behaviour of gelled, waxy North Sea crude oils. Journal of Petroleum Science and Engineering, 7(3-4), pp. 177-213, 1992.

[7] Al-Zahrani, S.M. \& Al-Fariss, T.F., A general model for the viscosity of waxy oils. Chemical Engineering and Processing: Process Intensification, 37(5), pp. 433-437, 1998.

[8] Adeyanju, O. \& Oyekunle, L., An Experimental Study of Rheological Properties of Nigerian Waxy Crude Oil. Petroleum Science and Technology, 30(11), pp. 1102-1111, 2012.

[9] Farina, A. \& Fasano, A., Flow characteristics of waxy crude oils in laboratory experimental loops. Mathematical and Computer Modelling, 25(5), pp. 75-86, 1997.

[10] Teng, H. \& Zhang, J., Viscoelasto-thixotropic model for waxy crude. Huagong Xuebao/CIESC Journal, 64(11), pp. 3968-3975, 2013. 
72 Computational and Experimental Methods in Multiphase and Complex Flow IX

[11] Li, H. \& Zhang, J.A., generalized model for predicting non-Newtonian viscosity of waxy crudes as a function of temperature and precipitated wax. Fuel, 82(11), pp. 1387-1397, 2003.

[12] Sifferman, T.R., Flow Properties of Difficult-To-Handle Waxy Crude Oils. Journal of PetroleumTechnology, pp. 1042-1050, 1979.

[13] Wardhaugh, L.T., Boger, D.V. \& Tonner, S.P., Rheology of Waxy Crude Oils, (SPE 17625), 1988.

[14] Hoshyargar, V., Marjani, A., Fadaei, F. \& Shirazian, S., Prediction of flow behavior of crude oil-in-water emulsion through the pipe by using rheological properties. Oriental Journal of Chemistry, 28(1), pp. 109-113, 2012.

[15] Visintin, R.F.G., Lapasin, R., Vignati, E., D’Antona, P. \& Lockhart, T.P., Rheological behavior and structural interpretation of waxy crude oil gels. Langmuir, 21(14), pp. 6240-6249, 2005.

[16] Johnsen, E.E. \& Rønningen, H.P., Viscosity of 'live' water-in-crude-oil emulsions: Experimental work and validation of correlations. Journal of Petroleum Science and Engineering, 38(1-2), pp. 23-36, 2003. 